\title{
Conscious sedation by Midazolam in pediatric odontology: A randomized clinical trial
}

\author{
Maria Mtalsi, Mouna Hamza, Fatima Ezzahra Elgasmi ${ }^{*}$, Amal Chlyah, Badreddine Hmamouchi ${ }^{2}$ and Samira \\ Elarabi
}
${ }^{1}$ Department of Pediatric Odontology, Dental Medicine Faculty, Hassan II University, Casablanca, 21100 Morocco. 2 Pediatric Resuscitation, Private Practice.

GSC Biological and Pharmaceutical Sciences, 2021, 14(02), 172-180

Publication history: Received on 19 January 2021; revised on 20 February 2021; accepted on 22 February 2021

Article DOI: https://doi.org/10.30574/gscbps.2021.14.2.0056

\begin{abstract}
Objectives: The objectives of this study are to evaluate the efficacy of midazolam as a means of conscious sedation in pediatric odontology through three routes of administration: oral, rectal and nasal administration, to compare the efficacy of these different routes and to assess the general safety of Midazolam.
\end{abstract}

Materials and Methods: Thirty healthy non-cooperating (ASAI) patients (levels 1 and 2 on the FRANKL scale), aged 2 to 5 years and requiring a minimum of three dental sessions were recruited. Each patient received three sessions of sedation, using a different route of administration each time: oral $(0.5 \mathrm{mg} / \mathrm{kg})$, rectal $(0.3 \mathrm{mg} / \mathrm{kg})$ and nasal $(0.2 \mathrm{mg} / \mathrm{kg})$. The assessment of the behavior throughout the dental care was made using the Houpt scale. Physiological parameters(heart rate and oxygen saturation) were measured every five minutes to assess tolerance.

Results: The three routes of administration of midazolam were considered effective since all patients presented a behavior allowing a complete management without interruption of care except for one patient. The sedative effect of the oral and rectal routes was similar, as to the nasal route, it was judged to be clinically better but without any statistically significant differences. The most accepted route of administration by patients was the oral one followed by the nasal and rectal routes. No intolerance to midazolam was observed.

Conclusion: Midazolam is an effective sedative for dental care, acceptable by patients and well tolerated regardless of the route of administration.

Keywords: Conscious sedation; Midazolam; Oral; Intranasal; Rectal; Child; Dentistry

\section{Introduction}

Despite the many improvements in anesthesia and dentistry techniques over the past few decades, oral and dental treatments remain a dreaded and sometimes insurmountable challenge for some children. Indeed, when a child is confronted to a dental care situation, his anxiety can cause profound emotional distress that increase the threshold of pain and modify his behavior on the dental chair $[1,2]$.

In the case of a patient who opposes dental treatment, the practitioner must be able to choose among several management modalities, ranging from cognitive behavioral techniques to various methods of conscious sedation until general anesthesia. Because of its pharmacokinetic properties, midazolam is an effective and well-tolerated method of conscious sedation for the young patient. Indeed, midazolam, which is a water-soluble benzodiazepine with a short

${ }^{*}$ Corresponding author: Fz Elgasmi

Department of Pediatric Odontology, Dental Medicine Faculty, Hassan II University, Casablanca, 21100 Morocco.

Copyright (C) 2021 Author(s) retain the copyright of this article. This article is published under the terms of the Creative Commons Attribution Liscense 4.0. 
duration of action, has anxiolytic, muscle relaxant and amnesic properties which are highly sought during a child dental care [3].

When administered orally, midazolam reaches its plasma peak concentration one hour later. However, this serum peak is reached faster after 9 to 39 minutes or even after 10 to 20 minutes when the midazolam is administered rectally or nasally, respectively $[3,4,5,6,7]$.

Although midazolam has been the subject of several publications evaluating its efficacy and tolerability, few studies have compared its use across different routes of administration as a means of sedation for children's dental care. Indeed, some authors have compared only two routes of administration (oral/nasal, rectal/oral) [8,9]. Other studies have compared several routes in a medical setting other than children's dental care, if not as a means of preparation for dental care under general anesthesia $[10,11,12]$.

Most pediatric anesthetists prefer non-invasive routes. Although the administration of midazolam via a non-invasive route is generally pain free, it might be associated with minor side-effects. Rectal midazolam administration has proven to be a reliable route. However, some children or their parents may find it distressing. Intranasal administration causes significant nasal irritation and watering eyes. Oral or sublingual routes require the child's cooperation [10].

The aim of this study was to compare the efficacy and tolerability of Midazolam as a means of conscious sedation in pediatric dentistry through three routes of administration: oral, rectal and nasal routes and to assess their level of acceptance.

\section{Material and methods}

A randomized, double-blind, clinical trial was conducted by the same pediatric dentist in collaboration with the anesthesia-intensive care department of Abderrahim Harouchi Children's Hospital wich is part of University Hospital of Casablanca in collaboration with the anesthesia-intensive care department of the same hospital.

Ethical clearance was obtained from the institution and parents or guardians of the children who participated in the study were provided with the necessary information, both orally and in writing, prior to obtaining signed written consent from the parents.

Thirty healthy patients (ASAI according to the classification of the American Society of Anesthetists), aged 18 months to 5 years, negative or completely negative (levels 1 or 2 according to the FRANKL scale), with no absolute or relative contraindications to midazolam and requiring at least three dental care sessions were selected for the study[3.8].

All patients with systemic health problems (ASAII, ASAIII), aged under 18 months or above 5 years, presenting absolute or relative contraindications to midazolam and whose parents refused the sedation procedure, were excluded from the study.

It was a double-blind, randomized study.

All children were referred to an anesthesiologist for a pre-sedation consultation and each received three dental care sessions under conscious sedation with Midazolam (Hypnovel ${ }^{\circledR} 1 \mathrm{mg} / \mathrm{ml}$ Sol Inj, Roche Products Ltd.). A single route of administration was chosen per session: the oral route at the rate of $0.5 \mathrm{mg} / \mathrm{kg}$, the rectal route at $0.3 \mathrm{mg} / \mathrm{kg}$ and the nasal route at the rate of $0.2 \mathrm{mg} / \mathrm{kg}$. The method of administration was decided after a random draw done at the beginning of the first sedation session $[5,6,9]$.

For the oral route, the contents of the ampoule for parenteral use were mixed with $30 \mathrm{ml}$ of fresh and sweet orange juice in order to dissipate its bitter taste and then given to the child with a spoon, a glass or a syringe depending on age and cooperation.[10] For the rectal route, the drug was administered using a syringe connected through a plastic tube to a silicone olive. Finally, for the intra-nasal form, midazolam was administered in drops by a syringe without needle, half the volume in each nostril.]

Once the medication was administered, the child and his / her parents were invited to sit in a quiet room during the latency period ( 30 minutes for the oral route, 20 minutes for the rectal route and 10 minutes for the nasal route). At the end and as soon as the first signs of sedation appeared, the child was taken to the treatment room and then connected to a pulse oximeter monitoring heart rate and oxygen saturation in blood. The dental procedure was the same for all 
patients and consisted after placing a mouth opener, performing a prophylactic brushing, applying topical anesthesia followed by local anesthesia, placing the dental dam and finally performing during the same dental care session (a conservative or pulp treatment and one or more extractions).Throughout the whole session, the operator maintained not only a visual contact with the patient but also a verbal one.

Acceptance of the midazolam route of administration was considered good when the medication was administered to the patient with no problem, average when the medication was administered after several negotiations and poor when the administration of the product was done under duress.

Sedation was assessed first by measuring the behavior of the child according to the modified Houpt scale which takes into account four parameters: Sleep, cries, movements and total behavior of the child, [8] the various levels of the scale were determined by the relative difficulty in performing dental treatment and secondarily by the physiological parameters (oxygen saturation and heart rate), that were reported using a pulse oximeter.

The patient's behavior was rated independently by two examinators (pediatric dentists) who weren't at known of the administered midazolam route.

The physiological monitoring was continuous (and recorded at 5 minutes intervals) and during all the steps described above.

\subsection{Statistical analysis}

The results were exploited using the EPI 6 software (EPI Info Version 6) with assistance from the Epidemiology and Biostatics Laboratory team of the Faculty of Dentistry, University Hassan II of Casablanca. The exploitation consisted in a calculation of the average of the scores and values of the recorded physiological parameters.

The data were analyzed by sequential analysis to determine if there were any significant differences between the three routes.

\section{Results}

The average age of children in this trial during the 90 sessions was 35.75 + /- 3 months with a female predominance of $61,5 \%$. They all came from a low socioeconomic level and in terms of oral health, had a severe form of early childhood caries.

During these sedation sessions, various acts (extractions, pulp treatments, conservative and prophylactic treatments) were performed (Fig. 1)

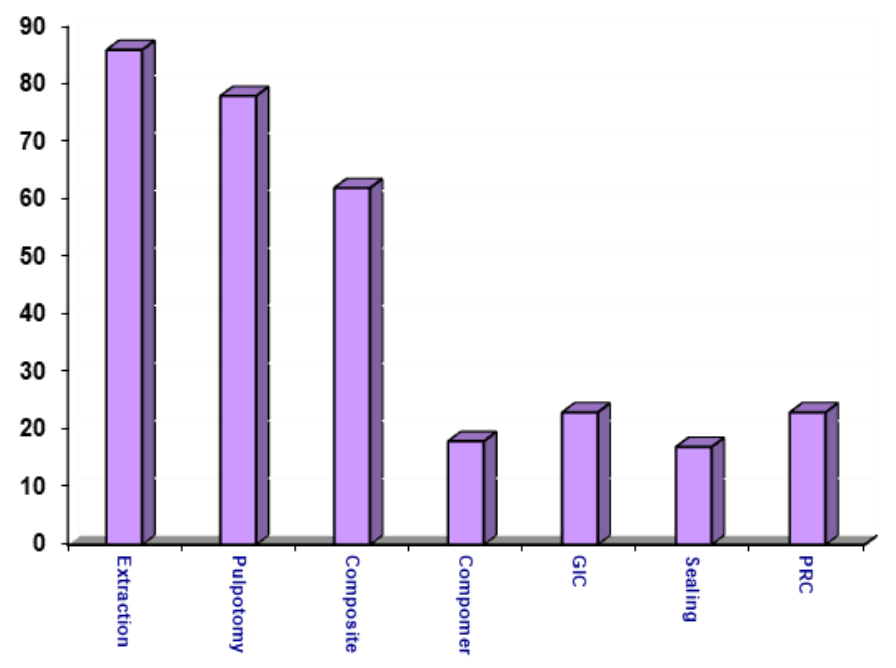

Figure 1 The different acts realized during sedation session 
The sleep assessment shows, for all three routes, that the children remained awake during the first ten minutes during which the operator performed the anesthesia and placed the dental dam. The state of somnolence (score 2 according to the modified Houpt scale) was generally obtained after fifteen minutes. No cases of falling asleep (score 4) were observed. (Fig. 2)
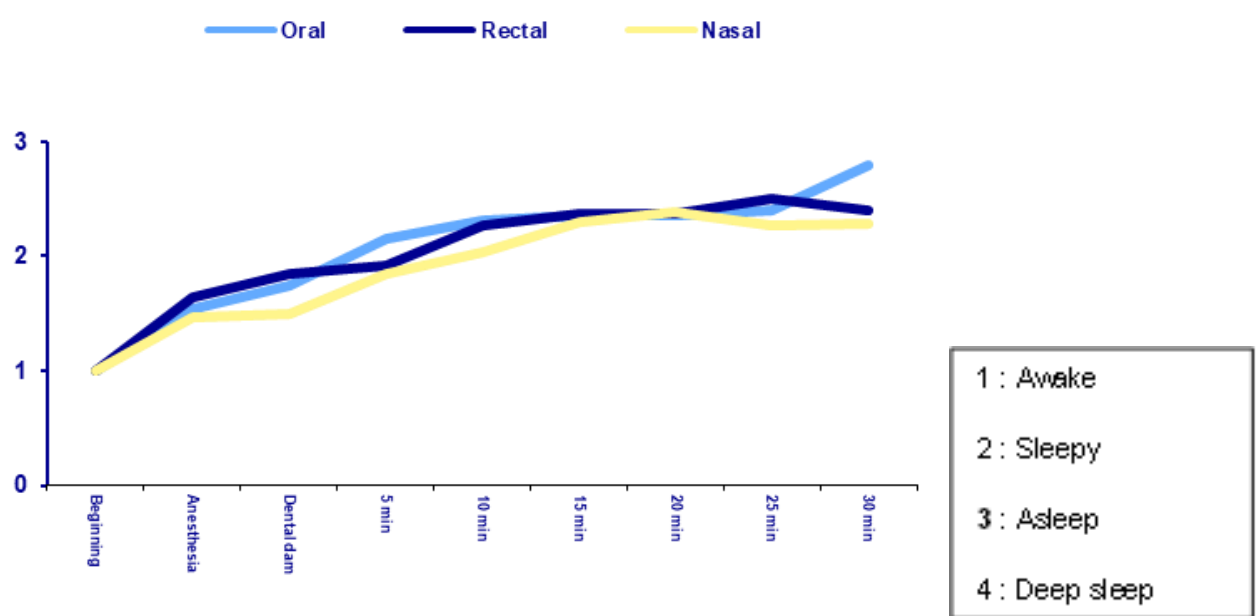

Figure 2 Evolution of sleep according to the modified Houpt scale of the three routes of administration

Figure 3 shows the presence of continuous movements (score 2) during the first minutes after the latency period and reaching a level of controllable or absent movements (score 3 to 4 ) from the fifteenth minute until the end of dental care for all three routes of administration.

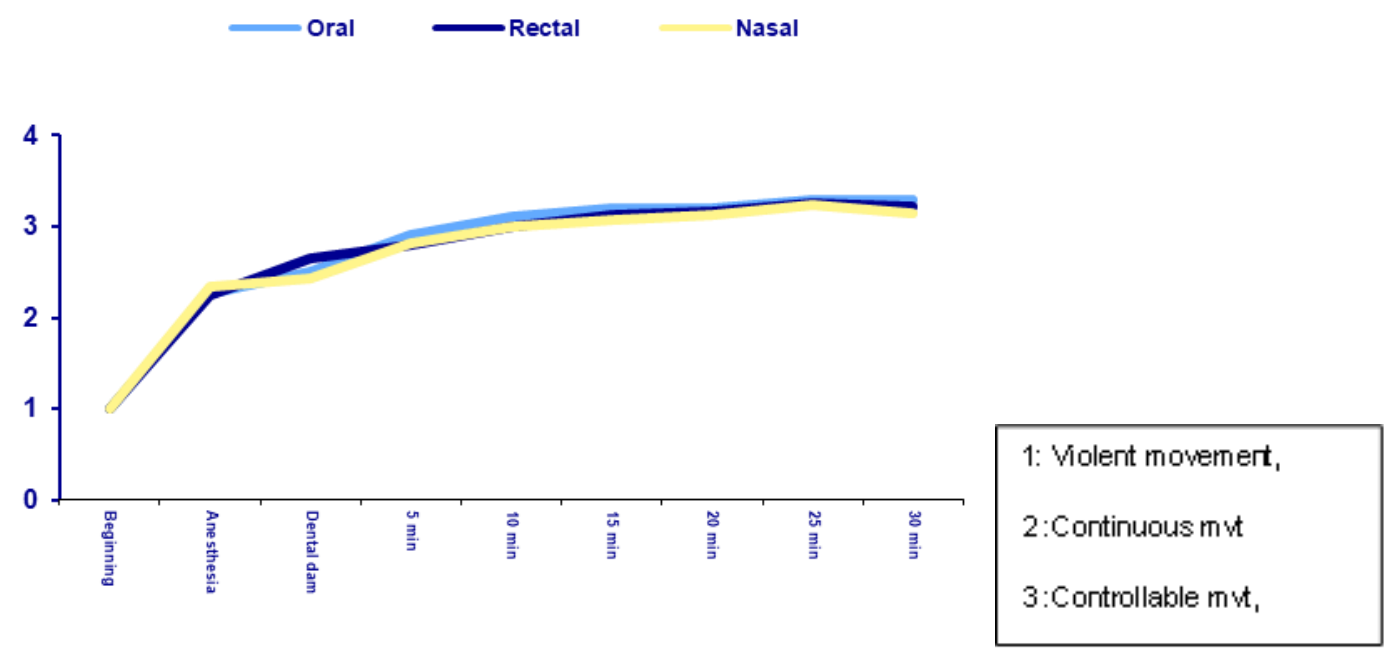

Figure 3 Evolution of movement according to the modified Houpt scale of the three routes of administration. 
The evaluation of cries during the dental care was similar to that of movements (Fig. 4).
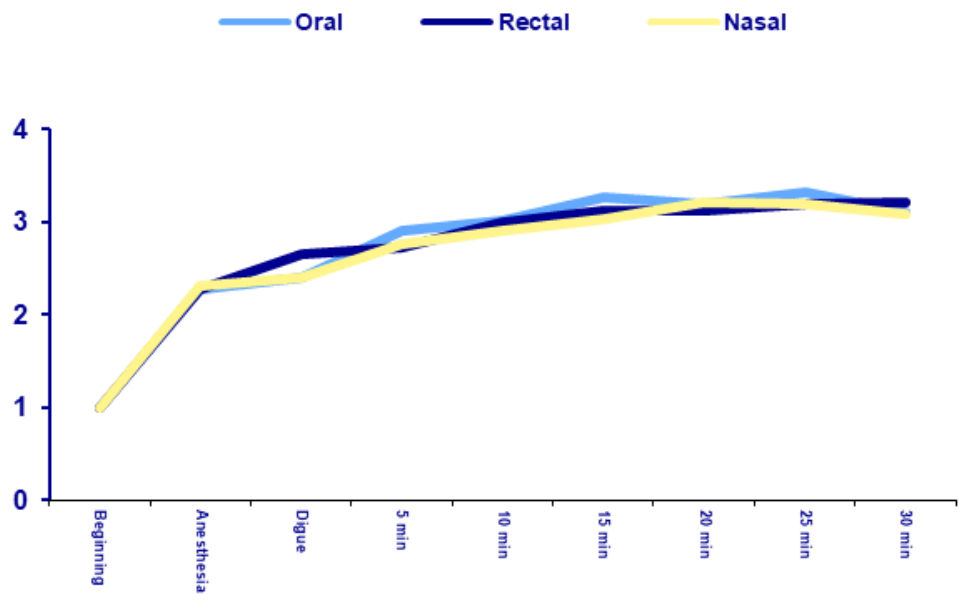

1: Hysterical cries,

2 : Continuous cries

3: Intermittent cries,

4: Absent cries

Figure 4 Evolution of cries according to the modified Houpt scale of the three routes of administration.

Concerning the overall behavior, a clear improvement was noticed. Children's behavior changed from a restless behavior (score 1) at the time of drug administration to good behavior just after the latency period and then to very good behavior (between score 4 and 5) during dental care (Fig. 5).
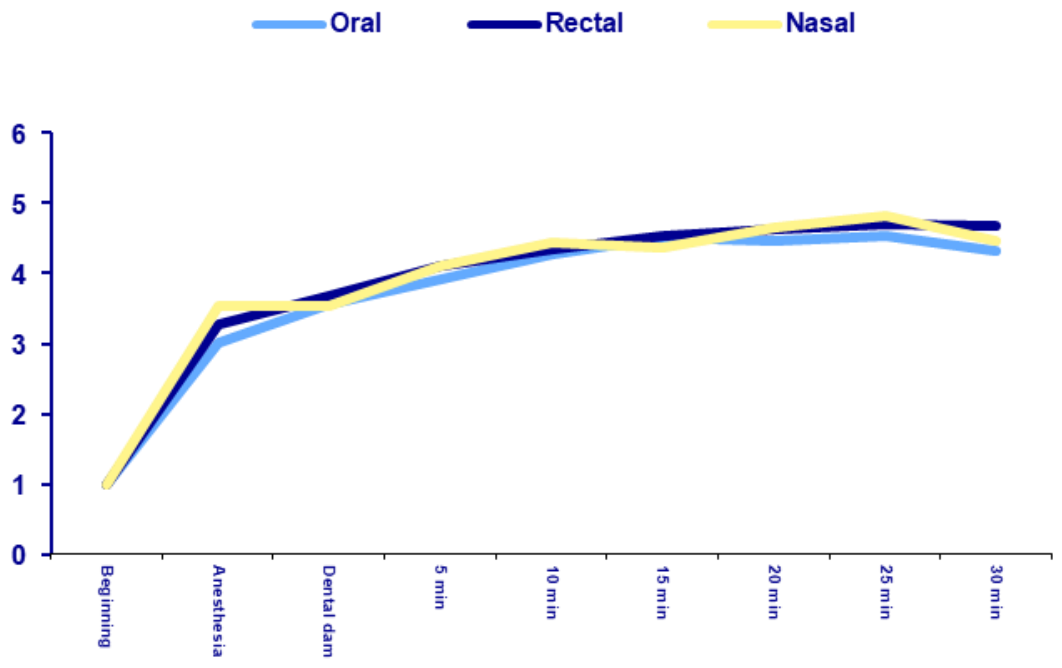

1 :Aborted behavior

2 :Poor behavior

3: Favorable behavior

$4:$ Good behavior

5 : Very good behavior

6: Excellent behavior

Figure 5 Evolution of overall behavior according to the modified Houpt scale of the three routes of administration

The same evolution of the various criteria assessing the behavior of the children (Sleep, movements, cries and total behavior) was observed for the three oral, rectal and nasal routes of administration.

As for the evaluation of the different routes acceptance, it was noted that the oral route was the most accepted followed by the nasal route and finally the rectal one (Fig. 6). 


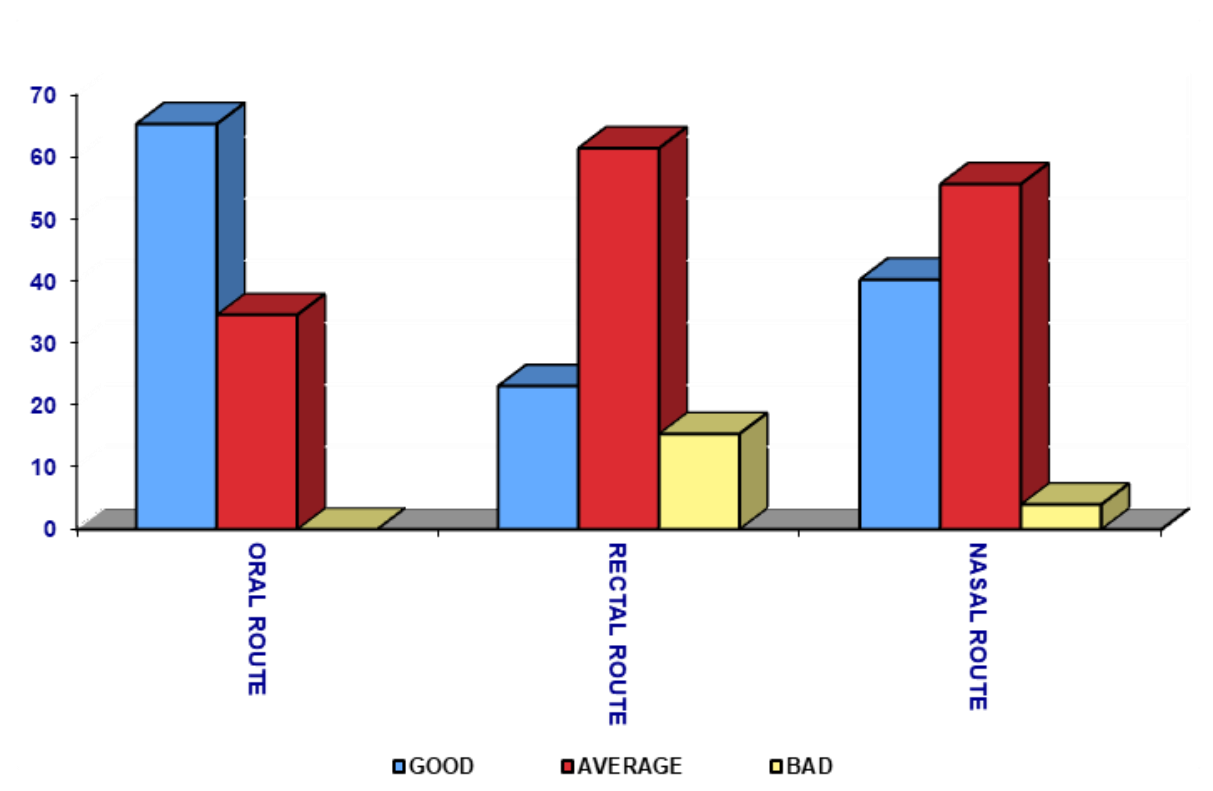

Figure 6 Evaluation of the level of acceptance according to the modified Houpt scale of the three routes of administration

To assess the tolerance of midazolam, two physiological parameters were observed every 5 minutes: the heart rate and oxygen saturation. The heart rate ranged from 112 to 122 beats / min with a peak when injecting anesthesia for all three routes of administration. The heart rate It slightly increased for the nasal route.. As for oxygen saturation, the mean values ranged between $98 \%$ and $99 \%$.

\section{Discussion}

The analysis of the different scores recorded during the behavioral evaluation according to the modified Houpt scale in the present study showed that the level of children cooperation was greatly improved throughout the dental care. In fact, at the end of 15 minutes after the latency period set for each mode of administration, the children were drowsy, had controllable or even absent movements, and cried only intermittently. The same evolution was observed for the three routes. This is in line with the results of the studies published in this direction: in fact Lourenço and al who evaluated the oral route and concluded that it is a safe and acceptable approach [13]. The study by Gilchristet and al, in 2004, found that nasal midazolam produces an adequate anxiolytic action[14]. Also AlSarheed ensured that intranasal midazolam was effective for modifying behavior in mild to moderately anxious children [15]. And finally the LindhStrömberg reported that sedation with midazolam rectally as a safe and effective means of sedation and that its large advantage is its short duration of action [16]. On the other hand Jensen and Matsson did not find a significant difference between oral $(0.4 \mathrm{mg} / \mathrm{kg})$ and rectal $(0.3 \mathrm{mg} / \mathrm{kg})[6]$. Similarly, Aydintug and al concluded that these two routes of administration are similar [8]. A comparison of the nasal and oral routes by Hartgraves and Primosch did not show any significant difference either [5]. However, Hosey and Blinkhorn, Lee-Kim and al, in a comparative study of the oral (0.7 $\mathrm{mg} / \mathrm{kg})$ and nasal $(0.3 \mathrm{mg} / \mathrm{kg})$ routes, found that the sedative state was obtained three times faster by the nasal route; as to the behavior, the result was similar for both modes of administration[17, 18$]$.

The fact that the nasal route makes it possible to obtain a more rapid sedation was taken into consideration from the outset in the operating protocol of our study, thus, the latency time for the oral route was twice as high as in the nasal route. In addition to the previous studies, Kogan and al found in a study evaluating four routes of administration (oral, rectal, nasal and sublingual) that there was no significant difference between these different routes [10]. In contrast, Chhibber and al concluded that the rectally administered midazolam was more effective compared to its oral or nasal effect [11]. However, in the latter two studies, the drug was used as a preparation for management under general anesthesia and not as a means of sedation for the realization of dental care in a completely different psychological context.

One of the important criteria considered in our study was the level of acceptance of the route of administration. We found that the oral route was the most accepted route, followed by the nasal and then the rectal route. As a matter of 
fact, the galenic form used, was the injectable one which is characterized by its bitter taste. Therefore, the use of a flavoring agent is essential. Some authors suggest the use of apple juice flavoring syrup [19, 20, 21, 22 ]. And others recommended syrups containing a pharmaceutical active agent such as hydroxyzine[5]. Our choice was for sweetened natural orange juice, available, popular and which could mask the unpleasant taste of midazolam without any synergistic effect of another pharmaceutical agent. Tolksdorf and Eick also found that the oral route is the most accepted followed by the nasal route and finally the rectal one [23]. The average level of acceptance of the nasal route is probably due to the tingling sensation and pain experienced following irritation of the nasal mucosa caused by direct contact with the concentrated product. To overcome this problem, some authors recommended the use of midazolam in a spray form $[13,23]$.

Although Jensen and Matsson didn't also find any difference of acceptance between the oral and rectal compared to the nasal and oral routes [6]. This observed difference of results is probably due to cultural and social differences specific to each population [23].

The evaluation of midazolam tolerance as a means of sedation in our study has allowed us to note that midazolam has no side effects. Heart rate and oxygen saturation were within the normal range of the child between the ages of 18 months and 5 years. Indeed, midazolam is the most frequently used benzodiazepine in dental sedation [24].It's tolerance depends on the route of administration and the dose used.

Studies have shown that oral, rectal and nasal routes do not produce any or very few side effects in the contrary of intravenous route [23-24-25-26-27-28-29-30-31-32]. In a country like ours where early childhood tooth decay is very common, access to dental care under general anesthesia remains difficult, midazolam sedation through the three routes of administration can be a good alternative to general anesthesia, effective and well tolerated, for the dental care of the young patient.

\section{Conclusion}

Administered under the required safety conditions, midazolam is an effective and well-tolerated means of sedation for dental care in young children regardless of oral, rectal or nasal route of administration. Although the oral route has a longer period of action, it remains the most accepted route followed by the nasal route and finally the rectal route.

\section{Compliance with ethical standards}

\section{Acknowledgments}

We would like to thank the following participating centers for their contributions to the success of this trial: Dental consultation and treatment center Casablanca and Abderrahim Harouchi Children's Hospital of the Ibn Rochd University Casablanca.

Funding was provided by the Dental consultation and treatment center of Casablanca in conjunction with the Abderrahim Harouchi Children's Hospital of the Ibn Rochd University of Casablanca.

\section{Disclosure of conflict of interest}

All authors declare that they have no conflict of interest.

\section{Statement of informed consent}

Informed consent was obtained from all individual participants included in the study

\section{References}

[1] Delcommune R. La phobie du chirurgien dentiste. Rev Odontostomatol (Paris). 1990;19(5):393-399.

[2] Boridy M, Charland R, Bourassa M. Fear of children at the dental office. A pain that isn't without remedy. J Dent Que. 1991; 28:265-270.

[3] Berthet A, Droz D, Manière MC, Naulin-Ifi C, Tardieu C, Le Traitement de la Douleur et de L'Anxiété: Chez L'Enfant. Quintssence International, Paris. 2006. 
[4] Bolon M, Boulieu R, Flamens C, Paulus S, Bastien O. Sedation induced by midazolam in intensive care: pharmacologic and pharmacokinetic aspects. Ann FrAnesthReanim. 2002;21(6):478-492.

[5] Hartgraves PM, Primosch RE. An evaluation of oral and nasal midazolam for pediatric dental sedation. ASDC J Dent Child. 1994;61(3):175-181.

[6] Jensen B, Matsson L. Oral versus rectal midazolam as a pre-anaesthetic sedative in children receiving dental treatment under general anaesthesia. ActaPaediatr. 2002;91(8):920-925.

[7] Fukuta 0, Braham RL, Yanase H, Kurosu K. Intranasal administration of midazolam: Pharmacokinetic and pharmacodynamic properties and sedative potential. ASDC J Dent Child. 1997;64(2):89-98.

[8] Aydintug YS, Okcu KM, Guner Y, Gunaydin Y, Sencimen M. Evaluation of oral or rectal midazolam as conscious sedation for pediatric patients in oral surgery. Mil Med. 2004;169(4):270-273.

[9] American Academy of Pediatric Dentistry. Behavior guidance for the pediatric dental patient. The Reference Manual of Pediatric Dentistry. Chicago, Ill.: American Academy of Pediatric Dentistry; 2020:292-310.

[10] Kogan A, Katz J, Efrat R, Eidelman LA. Premedication with midazolam in young children: A comparison of four routes of administration. PaediatrAnaesth 2002;12(8):685-689.

[11] Chhibber AK, Fickling K, Lustik SJ. Pre-anesthetic midazolam: A randomized trial with three different routes of administration. J Anesthe Clinic Res. 2011;2:118.

[12] Tolksdorf W, Eick C. Rectal.oral and nasal premedication using midazolam in children aged 1-6 years. A comparative clinical study. Anaesthesist. 1991;40(12):661-667.

[13] Lourenço-Matharu L, Roberts GJ. Oral sedation for dental treatment in young children in a hospital setting. Br Dent J. 2010; 209(7).

[14] Gilchrist F, Cairns AM, Leitch JA. The use of intranasal midazolam in the treatment of paediatric dental patients. Anaesthesia 2007;62(12):1262-1265

[15] AlSarheed MA. Intranasal sedatives in pediatric dentistry. Saudi Med J. 2016;37(9):948-956.

[16] Lindh-Strömberg U. Rectal administration of midazolam for conscious sedation of uncooperative children in need of dental treatment. Swed Dent J. 2001;25(3):105-111.

[17] Hosey MT, Blinkhorn AS. An evaluation of four methods of assessing the behaviour of anxious child dental patients. Int J Paediatr Dent. 1995;5(2): 87-95.

[18] Lee-Kim SJ, Fadavi S, Punwani I, Koerber A. Nasal versus oral midazolam sedation for pediatric dental patients. J Dent Child (Chic). 2004;71(2):126-130.

[19] Kaviani N, Shahtusi M, Haj NorousaliTehrani M, Nazari S. Effect of oral midazolam premedication on children's co-operation before general anesthesia in pediatric dentistry. J Dent (Shiraz). 2014;15(3):123-128.

[20] Hosey MT. UK National Clinical Guidelines in Pediatric Dentistry. Managing anxious children: The use of conscious sedation in paediatric dentistry. Int J Paediatr Dent. 2002;12(5):359-372.

[21] Feld LH, Negus JB, White PF. Oral midazolam preanesthetic medication in pediatric outpatients. Anesthesiology. 1990 Nov;73(5):831-4.

[22] Uldum B, Hallonsten AL, Poulsen S. Midazolam conscious sedation in a large Danish municipal dental service for children and adolescents. Int J Paediatr Dent. 2008;18(4):256-261.

[23] Tolksdorf W, Eick C. Rectal, oral and nasal premedication using midazolam in children aged 1-6 years. A comparative clinical study. Anaesthesist. 1991;40(12):661-667.

[24] Corcuera-Flores JR, Silvestre-Rangil J, Cutando-Soriano A, López-Jiménez J. Current methods of sedation in dental patients - A systematic review of the literature. Med Oral Patol Oral Cir Bucal. 2016;21(5):e579-e586.

[25] al-Rakaf H, Bello LL, Turkustani A, Adenubi JO. Intra-nasal midazolam in conscious sedation of young paediatric dental patients. Int J Paediatr Dent. 2001;11(1):33-40.

[26] Dallman JA, Ignelzi MA Jr, Briskie DM. Comparing the safety, efficacy and recovery of intranasal midazolam vs. oral chloral hydrate and promethazine. Pediatr Dent. 2001;23(5):424-430. 
[27] Jensen B, Schröder U, Månsson U. Rectal sedation with diazepam or midazolam during extractions of traumatized primary incisors: a prospective, randomized, double-blind trial in Swedish children aged 1.5-3.5 years. ActaOdontolScand. 1999;57(4):190-194.

[28] Leitch J. Use of oral midazolam in tooth extraction. Br Dent J. 2002;192(8):454.

[29] Hulland SA, Freilich MM, Sàndor GK. Nitrous oxide-oxygen or oral midazolam for pediatric outpatient sedation. Oral Surg Oral Med Oral Pathol Oral RadiolEndod. 2002;93(6):643-646.

[30] Primosch RE, Bender F. Factors associated with administration route when using midazolam for pediatric conscious sedation. ASDC J Dent Child. 2001;68(4):233-228.

[31] Reeves ST, Wiedenfeld KR, Wrobleski J, Hardin CL, Pinosky ML. A randomized double-blind trial of chloral hydrate/hydroxyzine versus midazolam/acetaminophen in the sedation of pediatric dental outpatients. ASDC J Dent Child. 1996;63(2):95-100.

[32] Blumer S, Peretz B, Zisman G, Ratson T. Effect of sedation with midazolam and time to discharge among pediatric dental patients. J ClinPediatr Dent. 2017;41(5):384-387. 